\title{
Synthesis of Chain Shuttling Organometallic Compounds Capable of Producing Triblock Polyolefins
}

\author{
Lixin Sun, ${ }^{1 *}$ Endre Szuromi, ${ }^{1}$ Thomas Karjala, ${ }^{1}$ Zhe Zhou, ${ }^{2}$ and Edmund Carnahan ${ }^{1}$ \\ ${ }^{1}$ Performance and Specialty Plastics R\&D, Dow Inc., 230 Abner Jackson Pkwy, Herbert H. Dow Building, \\ Lake Jackson, TX 77566
}

${ }^{2}$ Core R\&D, Dow Inc., 230 Abner Jackson Pkwy, Edgar C. Britton Building, Lake Jackson, TX 77566

\section{Contents:}

1. Materials $\quad$ S2

2. Synthesis of Zn DHCSA ( $n=5) \quad$ S3

3. Silica Treatment to Remove Catalyst $\quad$ S7

4. Synthesis of $\mathrm{Al} / \mathrm{Zn}$ mixed metal DHCSA with TVCH linker S8

5. Synthesis of $\mathrm{Al} / \mathrm{Zn}$ mixed metal DHCSA with decadiene linker $\quad$ S9

6. Analytical Methods $\quad$ S10

7. Batch Reactor Polymerization Procedure $\quad \mathrm{S} 12$

8. Theoretical number average molecular weight $\mathrm{M}_{\mathrm{n}(\text { theo) }} \quad \mathrm{S} 12$

9. TGIC and DSC Characterizations of Block Polymers S13 


\section{Materials}

Anhydrous toluene was purchased from Aldrich and further dried over alumina activated in a $250{ }^{\circ} \mathrm{C}$ oven for 5 hours. The Isopar E mixed alkanes solvent was purchased from ExxonMobil and passed through a drying column before use. Decadiene and 1,2,4-trivinylcyclohexane (TVCH) were purchased from Aldrich and dried over activated alumina before use. 5-Ethylidene-2-norbornene (ENB, mixture of endo and exo) was purchased from Aldrich and dried over DD6 ${ }^{1}$ before use. Diethylzinc (DEZ) and triethylaluminum (TEA) were purchased from Aldrich and used as received. Catalysts $5,{ }^{2} \mathbf{6},{ }^{3} \mathbf{7} \mathbf{4}^{5}$ and the borate activator $\left(\left[\mathrm{HNMe}\left(\mathrm{C}_{18} \mathrm{H}_{37}\right)_{2}\right]\left[\mathrm{B}\left(\mathrm{C}_{6} \mathrm{~F}_{5}\right)_{4}\right]\right){ }^{6}$ were purchased from a commercial source.

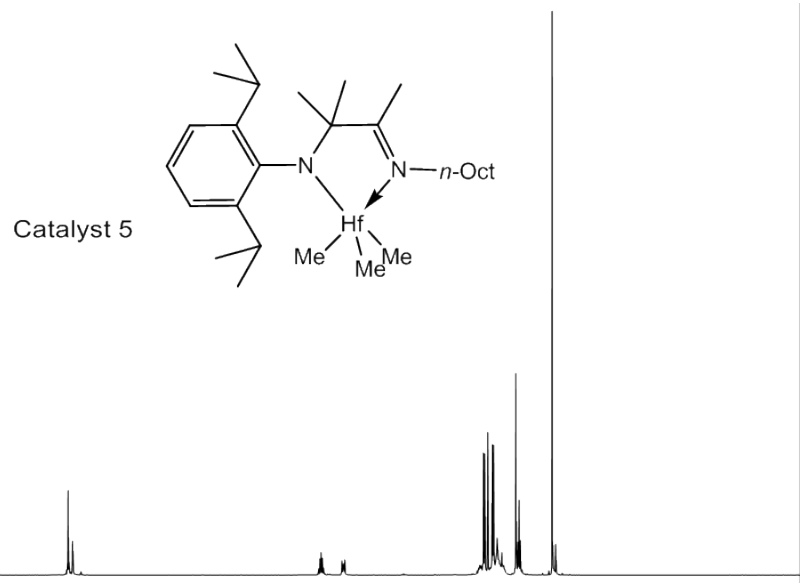

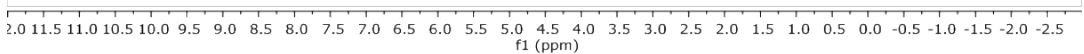

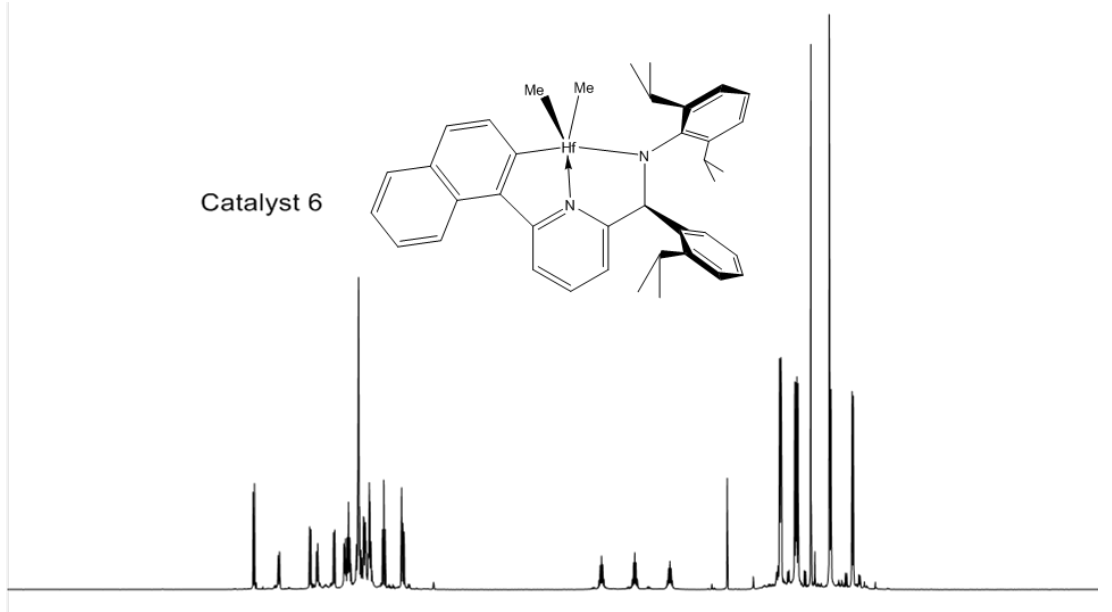

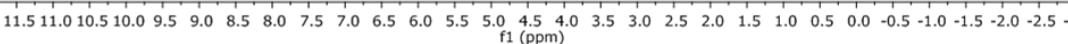




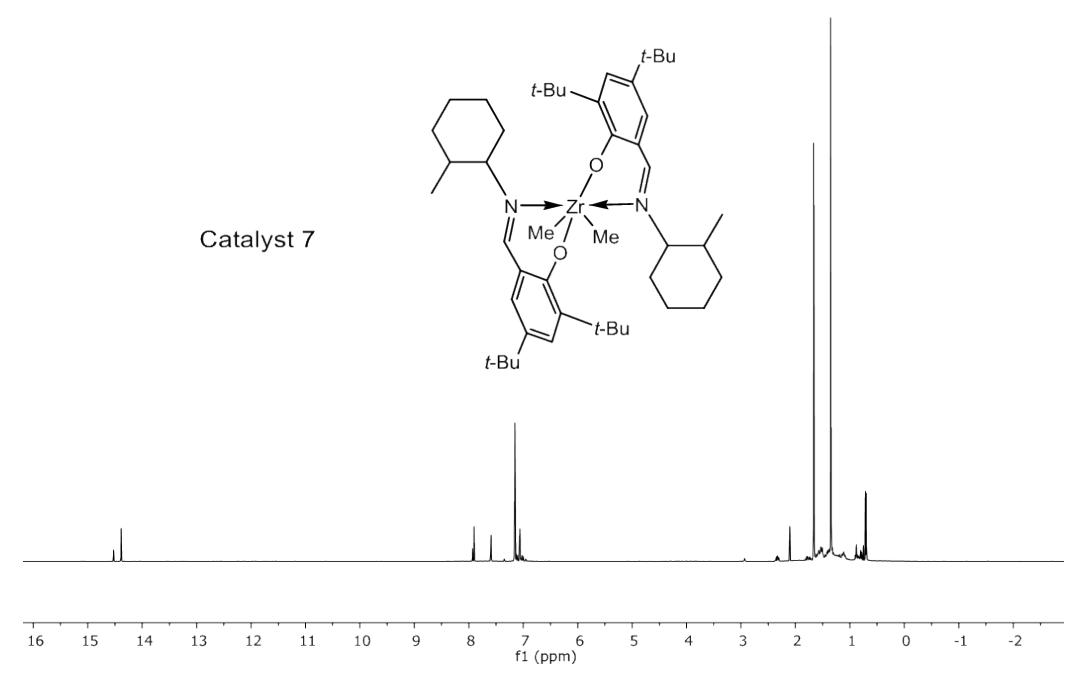

Figure $1 \mathrm{~S}^{1} \mathrm{H}$ NMR spectra of 5, 6 and 7

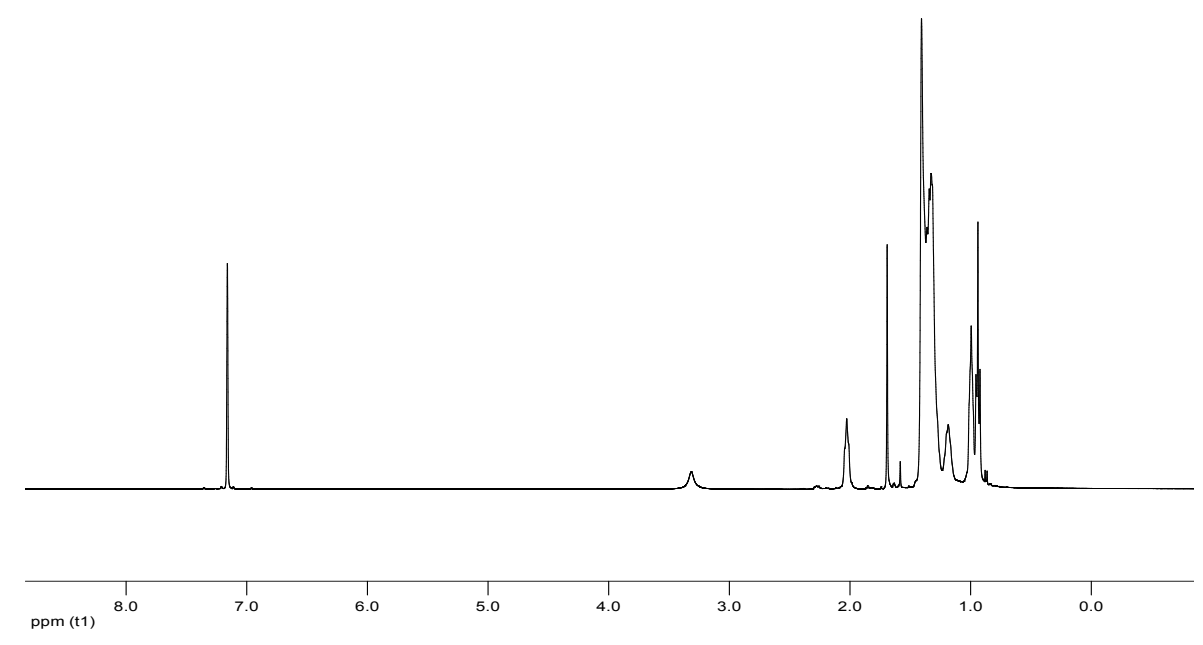

Figure $2 \mathrm{~S}^{1} \mathrm{H}$ NMR spectra of borate activator $\left[\mathrm{HNMe}\left(\mathrm{C}_{18} \mathrm{H}_{37}\right)_{2}\right]\left[\mathrm{B}\left(\mathrm{C}_{6} \mathrm{~F}_{5}\right)_{4}\right]$

Synthesis of Zn DHCSA ( $n=5)$

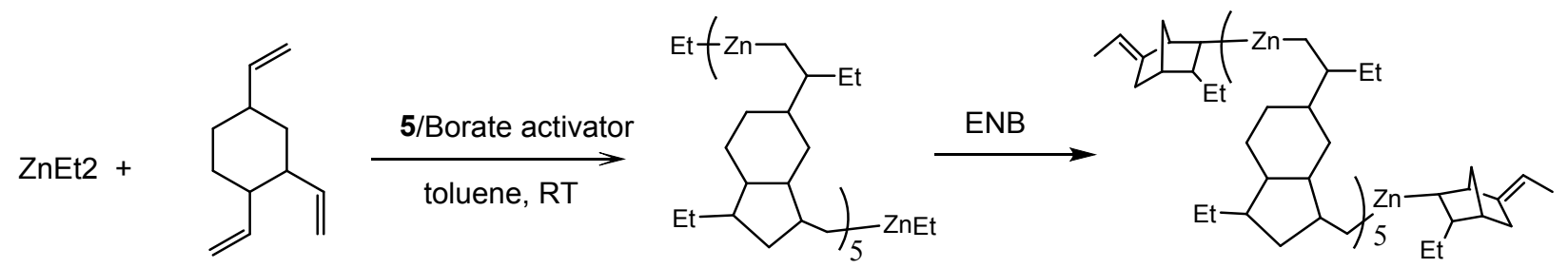

In a nitrogen-filled glove box, TVCH $(24.2 \mathrm{~mL}, 125 \mathrm{mmol}), \mathrm{DEZ}(15.4 \mathrm{~mL}, 150 \mathrm{mmol})$ and the borate 
activator (4.6 mL of $0.0644 \mathrm{M}$ solution in methylcyclohexane (MCH), $0.3 \mathrm{mmol}$ ) were added to $240 \mathrm{~mL}$ of toluene in a $500 \mathrm{~mL}$ round bottom flask equipped with a stir bar. An aliquot was taken and diluted with $\mathrm{C}_{6} \mathrm{D}_{6}$ for NMR spectroscopy. Catalyst 5 solution ( $120 \mathrm{mg}$ in $5 \mathrm{~mL}$ toluene, $0.25 \mathrm{mmol}$ ) was added dropwise to initiate the reaction and keep the temperature below $35{ }^{\circ} \mathrm{C}$. The mixture was stirred at room temperature for 2 hours. Samples were taken for $\mathrm{NMR}$ and quenched with $\mathrm{H}_{2} \mathrm{O}$ and $\mathrm{D}_{2} \mathrm{O}$ separately for GC/MS analysis. Compared to the sample before catalyst addition, the ${ }^{1} \mathrm{H}$ NMR spectrum showed that only a trace amount of vinyl unsaturation remained. Aliquots of the product solution were quenched separately with $\mathrm{H}_{2} \mathrm{O}$ and $\mathrm{D}_{2} \mathrm{O}$ for $\mathrm{GC} / \mathrm{MS}$ analysis. ENB $(6 \mathrm{~g}, 50 \mathrm{mmol})$ was added and the reaction was maintained for another two hours. In the end of reaction additional toluene was added to make the total volume to $300 \mathrm{~mL}$ with $[\mathrm{Zn}]$ of $0.5 \mathrm{M}$.

Each step of the reaction was minitored by ${ }^{1} \mathrm{H}$ NMR (Figure 3S) and GC/MS (Figure $4 \mathrm{~S}$ and 5S). The doublet peaks $(0.86 \mathrm{ppm})$ of the methyl group of methylcyclohexane, which was the solvent for the borate activator, was used as internal reference to estimate the consumption of DEZ. After the first step reaction with TVCH, the intensity of the ethyl zinc $(\mathrm{ZnCH} 2 \mathrm{CH} 3)$ peak at $\sim 0.1 \mathrm{ppm}$ reduced from 1.73 to 0.28 relative to the $\mathrm{MCH}$ reference peak. This $84 \%$ drop matches well the above reaction equation in which $5 / 6$ of ethyl zinc was consumed in the first step with TVCH. A new broad peaks formed at around 0.17-0.7 ppm attributed to $\mathrm{Zn}-\mathrm{CH} 2-\mathrm{R}$, where $\mathrm{CH} 2 \mathrm{R}$ represents the TVCH derived moiety between $\mathrm{Zn}$ metals. After reaction with ENB, the ethyl zinc peak at $0.1 \mathrm{ppm}$ disappeared completely, converting to $\mathrm{Zn}-\mathrm{CHR}^{\prime}$, where $-\mathrm{CHR}^{\prime}$ represents the norbornyl capping group.

After the first step, aliquats were quenched by $\mathrm{H}_{2} \mathrm{O}$ and $\mathrm{D}_{2} \mathrm{O}$ separately for $\mathrm{GC} / \mathrm{MS}$ analysis (Figure $4 \mathrm{~S}$ ). The $\mathrm{H}_{2} \mathrm{O}$-quenched sample showed a group of major peaks with $\mathrm{m} / \mathrm{z}=222$ and minor peaks with $\mathrm{m} / \mathrm{z}=$ 192. The former peaks are consistent to the TVCH derived cyclized fragment B (Figure 6S) and the latter minor peaks are consistent to the half converted TVCH mono-headed fragments A. Both molecules showed multiple peaks due to presence of multiple chiral centers in these structures. The tri-headed fragment $\mathbf{C}$ was not detected, suggesting that after vinyl insertion, intramolecular cyclization occurred with the remaining neighboring vinyl group. To confirm the connectivity of these fragments to $\mathrm{Zn}$ metal prior to hydrolysis, the aliquot quenched by $D_{2} \mathrm{O}$ was analyzed by GC/MS. The peaks at $\mathrm{m} / \mathrm{z}=222$ moved to 224 confirming the fragment was previously connected to two Zn metals. The peaks at $\mathrm{m} / \mathrm{z}=192 \mathrm{shifted}$ to 193 , confirming the species had single-point connection to $\mathrm{Zn}$.

Figure $5 \mathrm{~S}$ is the GC/MS chromatogram of the final product, showing additional group of peaks with $\mathrm{m} / \mathrm{z}$ of 150, consistent to the ENB derived capping group D. No starting ENB was detected, confirming that the 
second step reaction was complete.

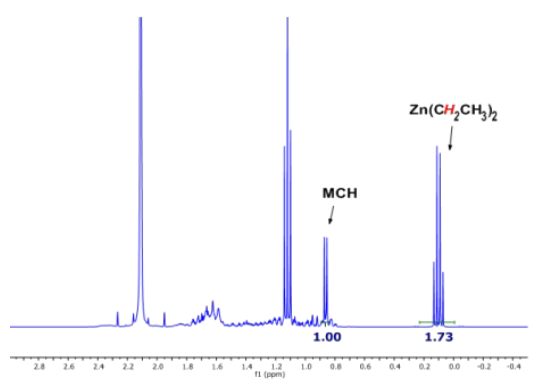

(A)

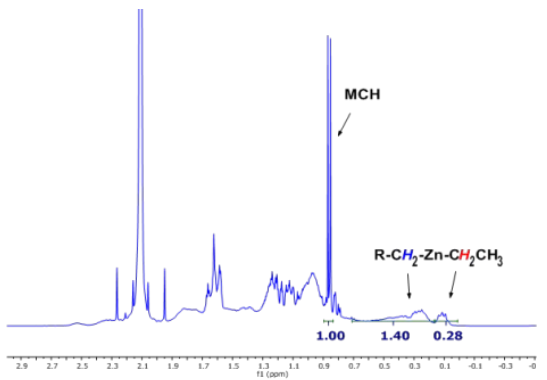

(B)

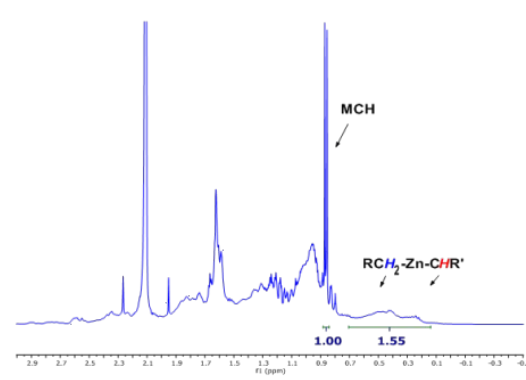

(C)

Figure 3S. ${ }^{1} \mathrm{H}$ NMR spectra of DHCSA. (A) before addition of procatalyst 5 , (B) after the first step of reaction, $(C)$ after the second step of reaction

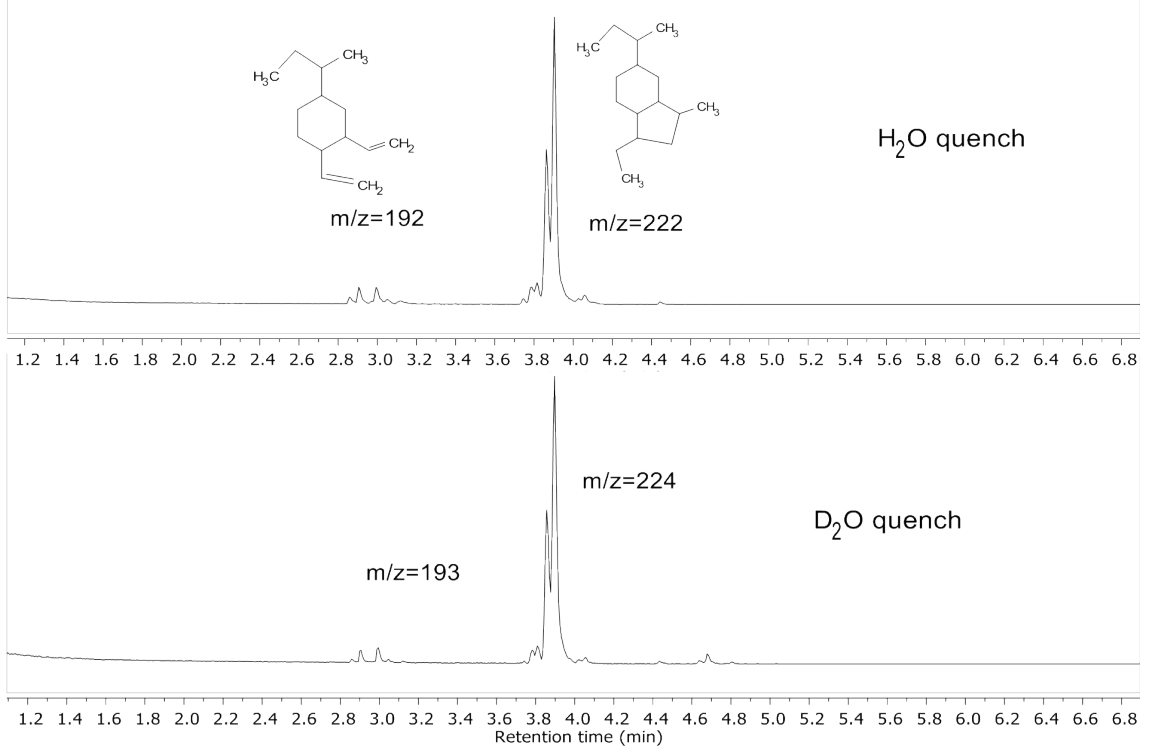

Figure 4S GC/MS chromatograms of DHCSA after first step reaction 


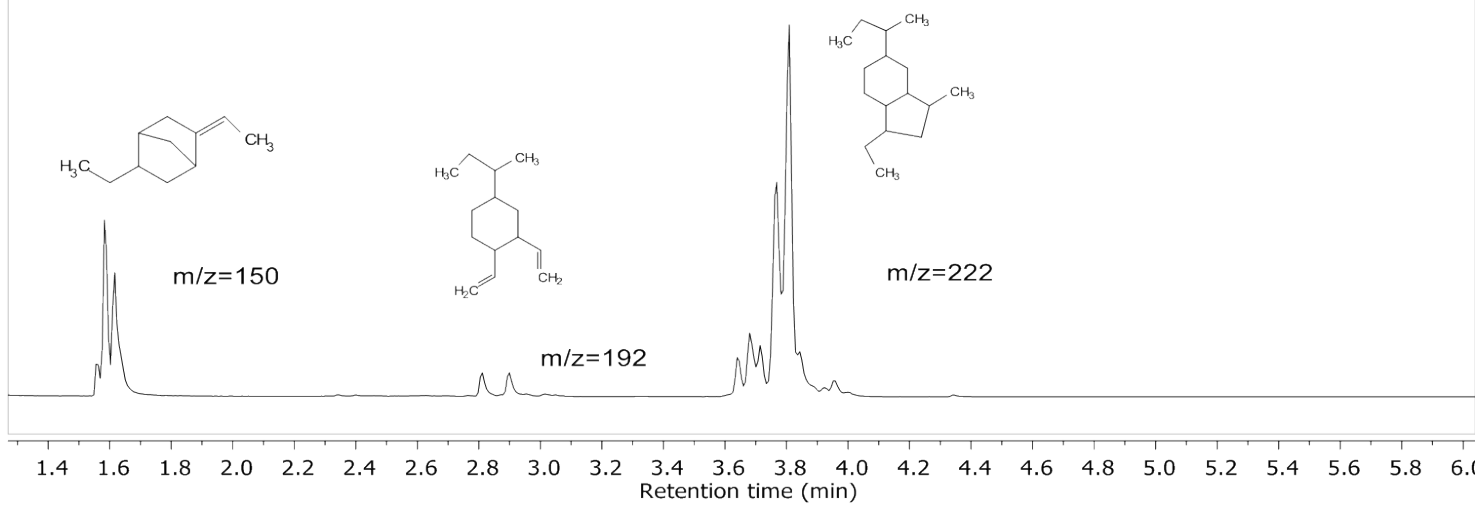

Figure 5S GC/MS chromatogram of the final product

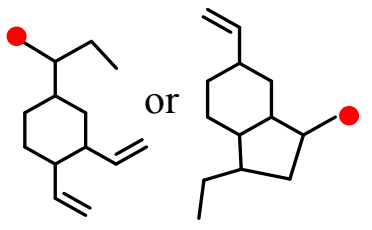

A

MW: 192

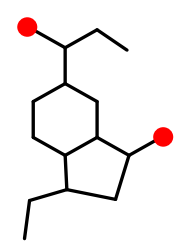

B

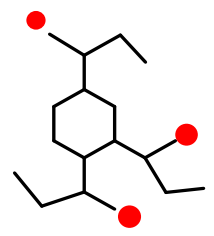

C, nd

MW: $222 \quad$ MW: $252 \quad$ MW: 150

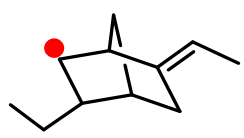

D

Figure 6S. Possible fragments after hydrolyzed. The red dot indicates the connectivity to $\mathrm{Zn}$ prior to hydrolysis. C was not detected.

To further probe structure $\mathbf{B}$ in Figure $6 \mathrm{~S}$, a larger portion of step 1 product was quenched with $\mathrm{D}_{2} \mathrm{O}$, washed with water $/ \mathrm{HCl}$, and extracted with hexane. The organic phase was isolated and the solvent was removed under vacuum to obtain a crude product for ${ }^{13} \mathrm{C}$ NMR analysis. The deuterium-labeled carbons shifted slightly upfield and split into three peaks, readily distinguishable from the unlabeled carbons. Theoretically, intramolecular cyclization could happen via 2,1-insertion of the remaining vinyl group to form a 6/6 ring structure or 1,2-insertion to form a 6/5 ring structure. The ${ }^{13} \mathrm{C}$ NMR spectrum in Figure $7 \mathrm{~S}$ is consistent with the $6 / 5$ ring structure $\mathbf{B}$ with two labeled primary carbons of equal intensity $\left(\mathrm{CH}_{2} \mathrm{D}(1): \mathrm{CH}_{2} \mathrm{D}(2)=1\right)$. The ratio of total $\mathrm{CH}_{2} \mathrm{D}$ to the ethyl groups (12-13 ppm) is also close to 1 . No $\mathrm{CHD}$ signal (indicative of the $6 / 6$ ring structure) was detected. 


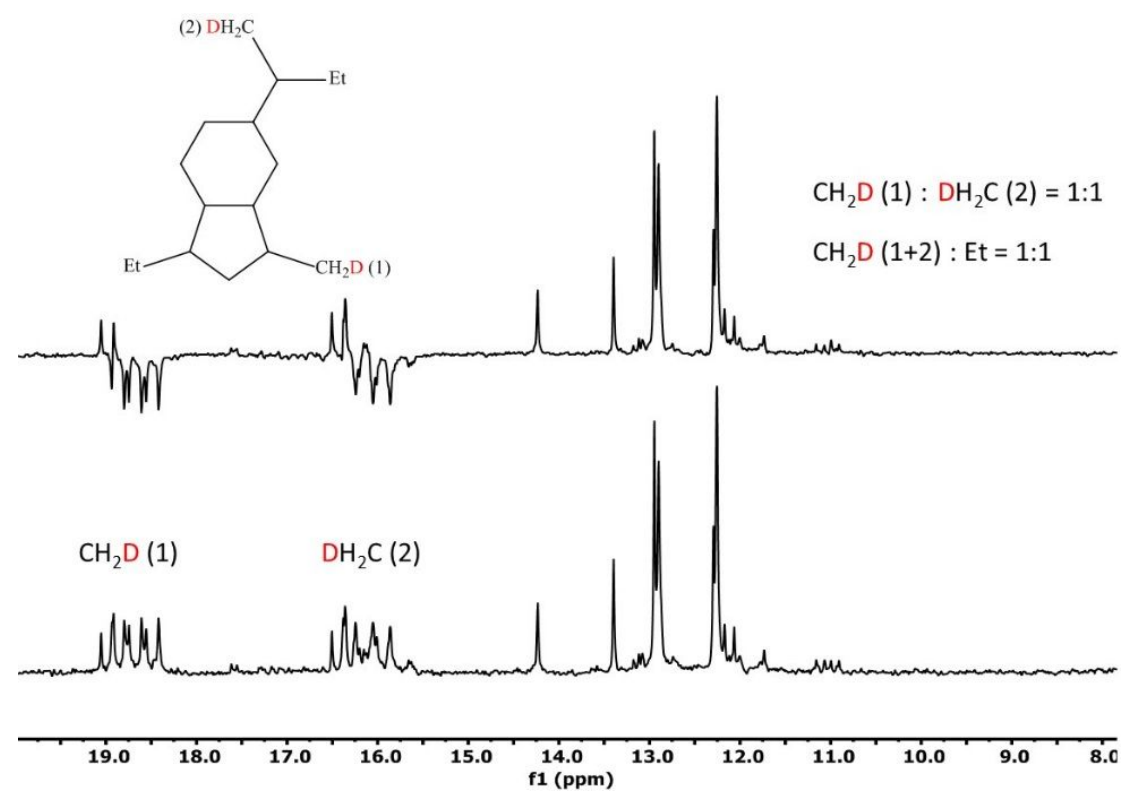

Figure 7S. ${ }^{13} \mathrm{C}$ NMR spectrum (bottom) and DEPT-135 (top) of the organic product isolated from $\mathrm{D}_{2} \mathrm{O}$ quenched DHCSA. Note that the D-labelling was not fully completed leaving a small fraction of unlabeled $\mathrm{CH}_{3}$ groups.

\section{Silica Treatment to Remove Catalyst}

Optionally, the residual catalyst in DHCSA can be removed by passing the solution through calcinated silica (ES757 from Ineos Silicas) without loss and degradation of the Zn DHCSA. The silica needs to be calcinated at over $600{ }^{\circ} \mathrm{C}$ to remove most of $\mathrm{OH}$ groups, leaving the strained Si-O-Si groups to absorb or decompose the oxophilic transition metal catalyst without compromising the organozinc species. Shown in Figure $8 \mathrm{~S}$ are images and GS/MS chromatograms of a Zn DHCSA $(n=1)$. The original yellow solution became colorless after treatment with calcinated silica, while the $\mathrm{Zn}$ compound composition remained intact, as evidenced by GC/MS analysis using dodecane as an internal standard. ${ }^{1} \mathrm{H}$ NMR analysis (Figure 9S) showed that the $\mathrm{Zn}-\mathrm{CH}_{2}$ - broad peak remained unchanged, indicating that the $\mathrm{Zn}$ compound was not compromised. 


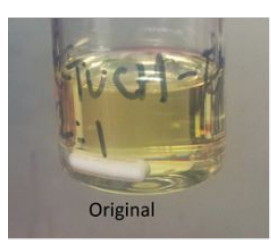

\section{Hydrolysis}
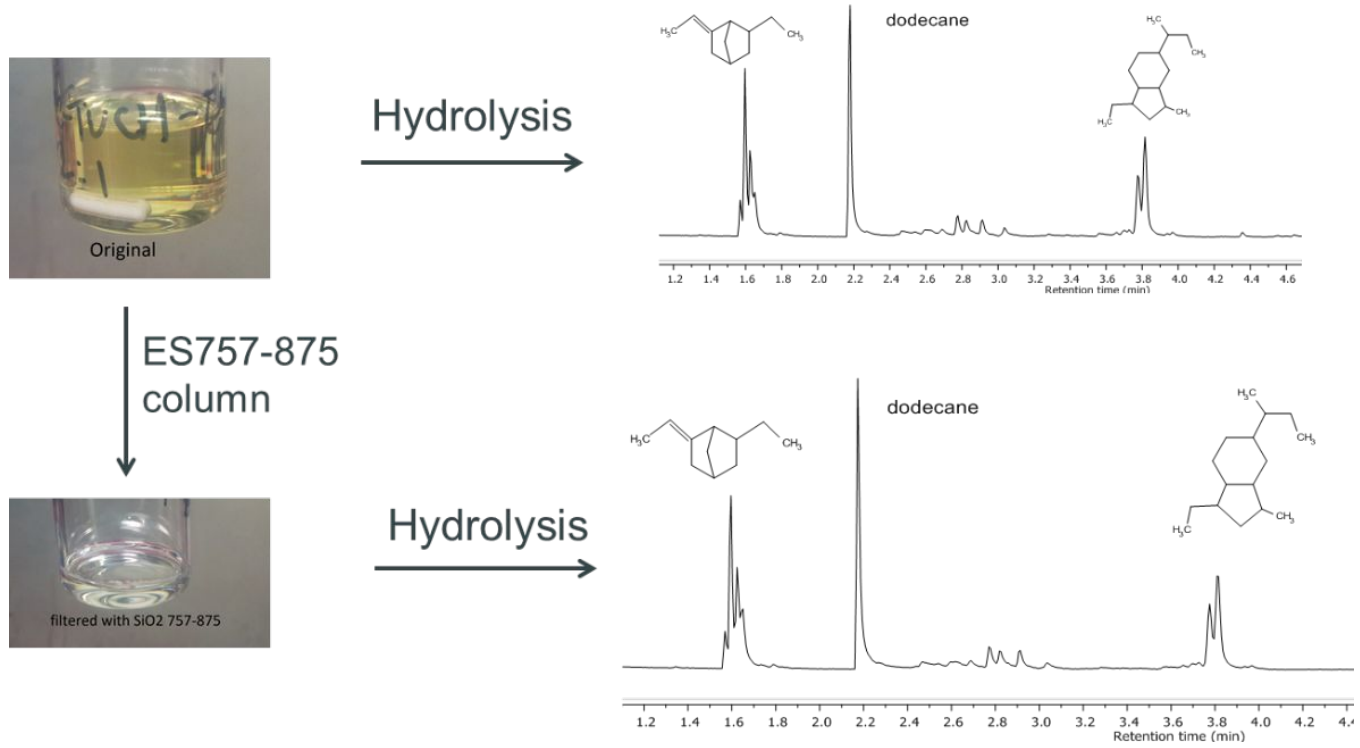

Figure $\mathbf{8 S}$. GC/MS analysis of DHCSA $(n=1)$ before and after calcinated silica treatment

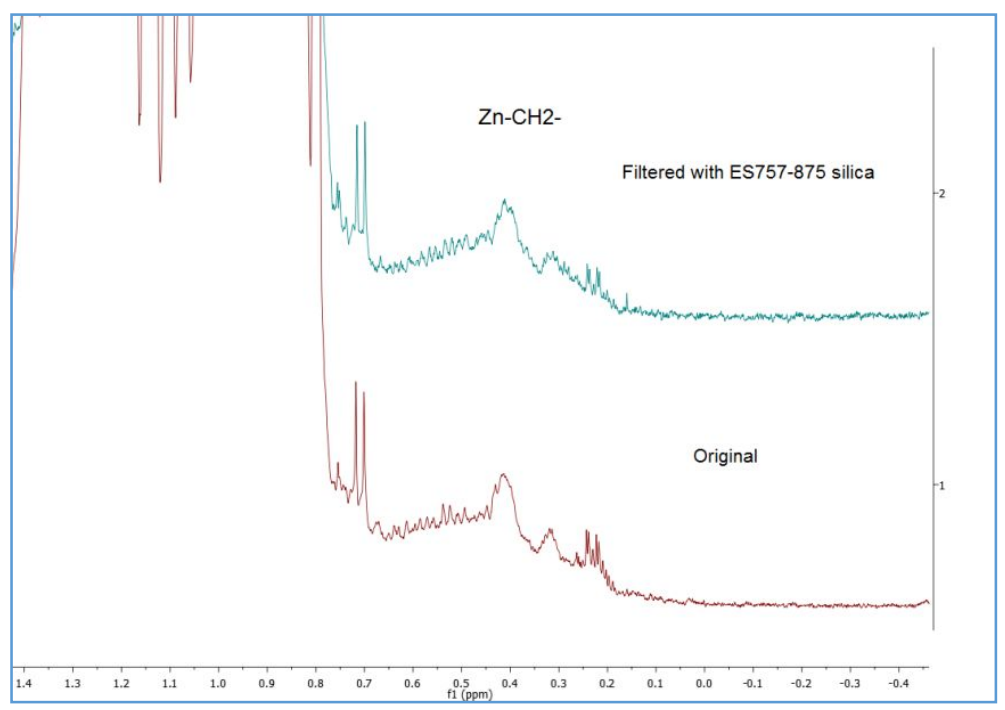

Figure 9S. ${ }^{1} \mathrm{H}$ NMR of DHCSA before and after calcinated silica treatment

\section{Synthesis of Al/Zn mixed metal DHCSA with TVCH linker}

In a nitrogen-filled glove box, TVCH $(0.49 \mathrm{~mL}, 2.53 \mathrm{mmol})$, diethylzinc $(0.1 \mathrm{~mL}, 0.97 \mathrm{mmol})$, triethylaluminum (1.94 mLof $1 \mathrm{M}$ solution in hexane, $1.94 \mathrm{mmol})$ and the borate activator $(0.362 \mathrm{~mL}$ of $0.0644 \mathrm{M}$ solution in $\mathrm{MCH}, 0.0233 \mathrm{mmol}$ ) were added to $6 \mathrm{~mL}$ of toluene. An aliquot was diluted with 
$\mathrm{C}_{6} \mathrm{D}_{6}$ for ${ }^{1} \mathrm{H}$ NMR analysis. Catalyst 5 (10 mg in $1 \mathrm{~mL}$ toluene) was added to initiate the reaction. After 75 min, aliquots were taken for ${ }^{1} \mathrm{H}$ NMR and GC/MS analyses, showing that TVCH was all consumed. The solution was brownish and clear (free of gels). ENB (0.327 g, $2.72 \mathrm{mmol}$ ) was added. After another $3 \mathrm{~h}$, aliquots were taken for ${ }^{1} \mathrm{H}$ NMR and GC/MS analyses. NMR showed that all M-Et ( $\mathrm{M}$ is $\mathrm{Zn}$ or $\mathrm{Al}$ ) and the endocyclic double bond of ENB were consumed. The hydrolyzed sample solution was cloudy. GC/MS showed one group of peaks at $\mathrm{m} / \mathrm{z}=150$ and one group of peaks at $\mathrm{m} / \mathrm{z}=222$.

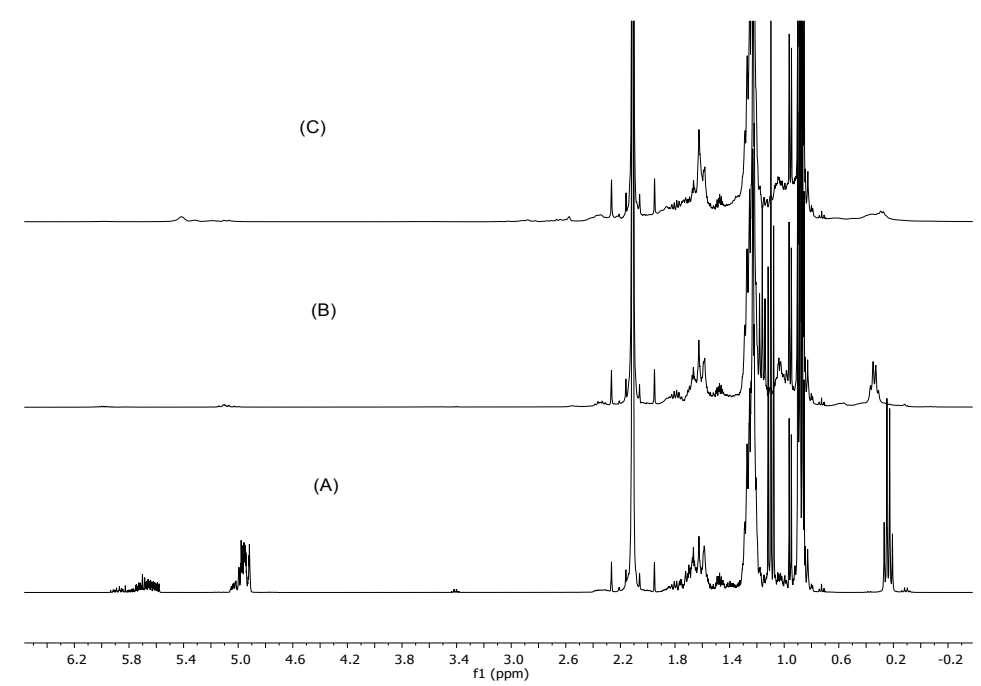

Figure $10 \mathrm{~S}^{1} \mathrm{H}$ NMR of TVCH-derived DHCSA solutions. (A) before reaction; (B) after $1^{\text {st }}$ step reaction; (C) after $2^{\text {nd }}$ step reaction

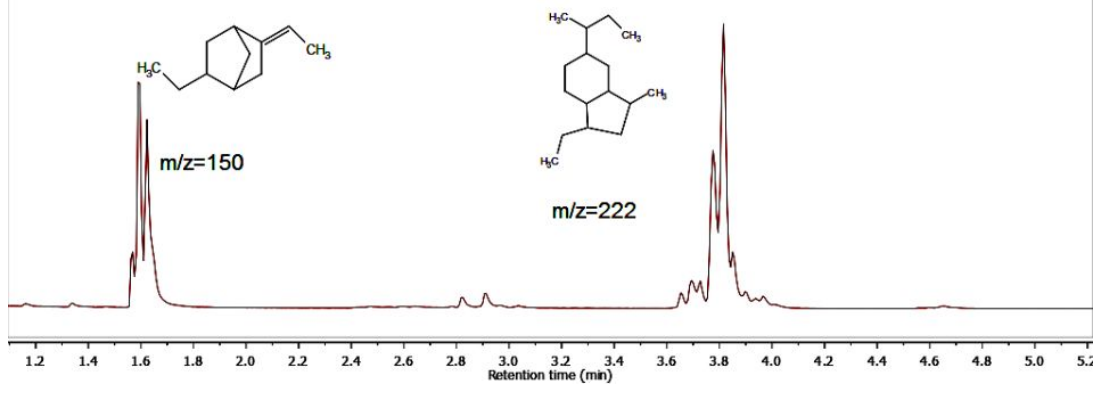

Figure 11S GC/MS chromatogram of hydrolyzed TVCH based Al/Zn DHCSA.

\section{Synthesis of $\mathrm{Al} / \mathrm{Zn}$ mixed metal DHCSA with decadiene linker}

In a nitrogen-filled glove box, decadiene $(0.466 \mathrm{~mL}, 2.53 \mathrm{mmol})$, diethylzinc $(0.1 \mathrm{~mL}, 0.97 \mathrm{mmol})$, triethylaluminum (1.94 $\mathrm{mL}$ of $1 \mathrm{M}$ solution in hexane, $1.94 \mathrm{mmol})$ and the borate activator $(0.362 \mathrm{~mL}$ of $0.0644 \mathrm{M}$ solution in $\mathrm{MCH}, 0.0233 \mathrm{mmol}$ ) were added to $6 \mathrm{~mL}$ of toluene. An aliquot was diluted with 
$\mathrm{C}_{6} \mathrm{D}_{6}$ for ${ }^{1} \mathrm{H}$ NMR analysis. Catalyst $5(10 \mathrm{mg}$ in $1 \mathrm{~mL}$ toluene, $0.017 \mathrm{mmol})$ was added to initiate the reaction. After $1 \mathrm{~h}$, the ${ }^{1} \mathrm{H}$ NMR analysis of an aliquot showed that decadiene was consumed. The solution was brownish and clear (free of gels). ENB $(0.327 \mathrm{~g}, 2.72 \mathrm{mmol}$ ) was added. After another $1.5 \mathrm{~h}$, aliquots were taken for ${ }^{1} \mathrm{H} N M R$ and GC/MS analyses. ${ }^{1} \mathrm{H}$ NMR showed that all M-Et (M is $\mathrm{Zn}$ or Al) was consumed. GC/MS showed a major group of peaks at $\mathrm{m} / \mathrm{z}=150$ and a clean single peak at 198.

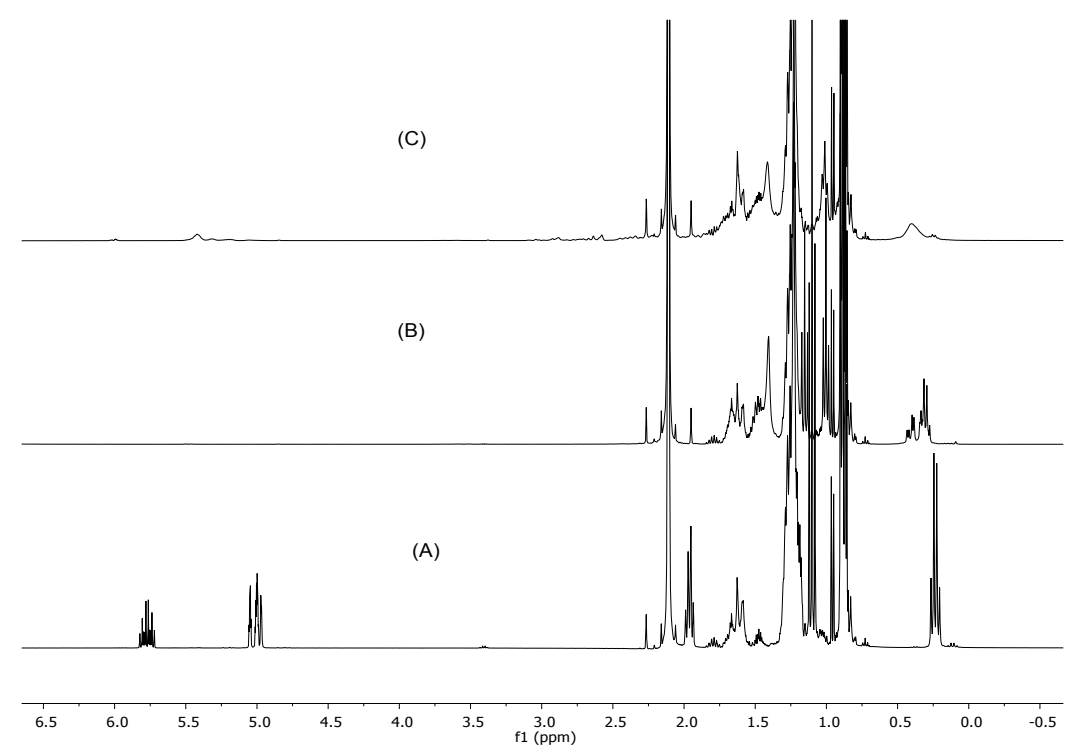

Figure $12 \mathrm{~S}^{1} \mathrm{H}$ NMR of decadiene-based DHCSA solutions. (A) before reaction; (B) after $1^{\text {st }}$ step reaction; (C) after $2^{\text {nd }}$ step reaction

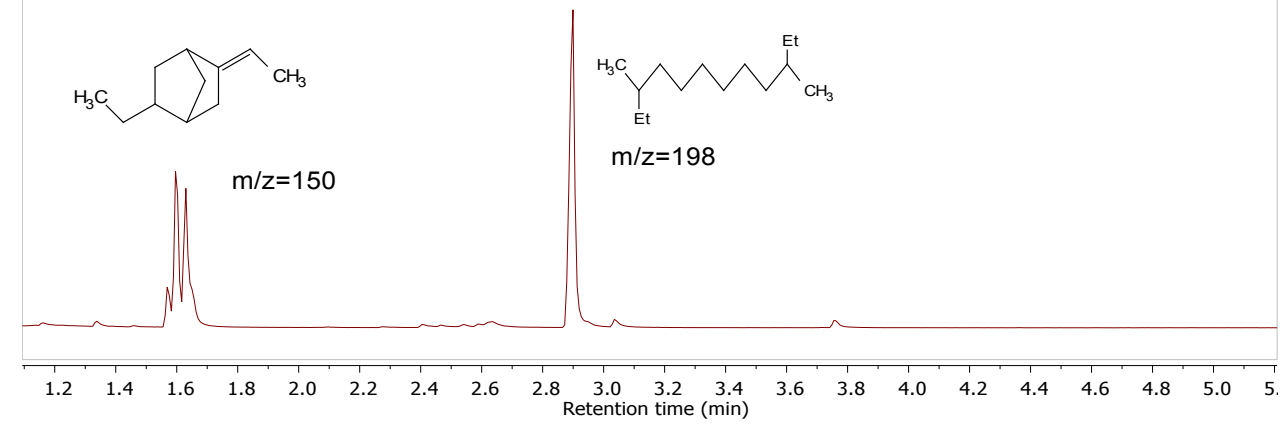

Figure $135 \mathrm{GC} / \mathrm{MS}$ chromatogram of hydrolyzed decadiene-derived Al/Zn DHCSA

\section{Analytical Methods}

${ }^{1} \mathrm{H}$ NMR: ${ }^{1} \mathrm{H}$ NMR spectra were recorded on a Bruker AV-400 spectrometer at room temperature. ${ }^{1} \mathrm{H}$ NMR 
chemical shifts in benzene- $d_{6}$ were referenced to $7.16 \mathrm{ppm}\left(\mathrm{C}_{6} \mathrm{D}_{5} \mathrm{H}\right)$.

${ }^{13} \mathrm{C}$ NMR: ${ }^{13} \mathrm{C}$ NMR spectra of polymers were collected using a Bruker $400 \mathrm{MHz}$ spectrometer equipped with a Bruker DUL high-temperature CryoProbe. The polymer samples were prepared by adding approximately $2.6 \mathrm{~g}$ of a $50 / 50$ mixture of tetrachloroethane- $\mathrm{d}_{2} /$ orthodichlorobenzene containing $0.025 \mathrm{M}$ chromium triacetylacetonate (relaxation agent) to $0.2 \mathrm{~g}$ of polymer in a $10 \mathrm{~mm}$ NMR tube. The samples were dissolved and homogenized by heating the tube and its contents to $135{ }^{\circ} \mathrm{C}$. The data was acquired using 320-8000 scans per data file with an inverse gated pulse and a 7.3 s pulse repetition delay with a sample temperature of $120^{\circ} \mathrm{C}$.

GC/MS: Tandem gas chromatography/low resolution mass spectroscopy using electron impact ionization (EI) was performed at $70 \mathrm{eV}$ on an Agilent Technologies $6890 \mathrm{~N}$ series gas chromatograph equipped with an Agilent Technologies 5975 inert XL mass selective detector and an Agilent Technologies Capillary column (HP1MS, $15 \mathrm{~m} \times 0.25 \mathrm{~mm}, 0.25$ micron). Oven Equilibration Time: $0.5 \mathrm{~min}, 50^{\circ} \mathrm{C}$ for $0 \mathrm{~min}$, then 25 ${ }^{\circ} \mathrm{C} / \mathrm{min}$ to $200{ }^{\circ} \mathrm{C}$, hold time: $5 \mathrm{~min}$, total run time: $11 \mathrm{~min}$.

DSC: Differential Scanning Calorimetry (DSC) was performed on a TA Instruments Q100 DSC V7.0. Samples were initially annealed at $150^{\circ} \mathrm{C}(3 \mathrm{~min})$ after which they were cooled at $10^{\circ} \mathrm{C} / \mathrm{min}$ to $-90{ }^{\circ} \mathrm{C}$ to afford "cooling" DSC data. After a $5 \mathrm{~min}$ hold, the samples were heated to $150^{\circ} \mathrm{C}$ at $10^{\circ} \mathrm{C} / \mathrm{min}$ to collect "heating" DSC data.

TGIC: A commercial Crystallization Elution Fractionation instrument (CEF) (Polymer Char, Spain) was used to perform the high temperature thermal gradient interaction chromatography (TGIC) measurement. A Hypercarb column (100 X 4.6 mm, Part\# 35005-104646, Thermo Scientific) was use for the separation. A "8 cm X $0.48 \mathrm{~cm}$ (3/16 inch ID)" stainless steel column packed with 27 micron glass beads ( Catalog\# GL01918/20-27um, MO-SCI Specialty Products, LLC, Rolla, MO, USA), was installed in front of IR detector, in the top oven of the CEF instrument. The experimental parameters were: a top oven/transfer line/needle temperature at $150{ }^{\circ} \mathrm{C}$, a dissolution temperature at $160^{\circ} \mathrm{C}$, a dissolution stirring setting at 2 , a sample loading volume of $0.400 \mathrm{~mL}$, a pump stabilization time of 15 seconds, a pump flow rate for cleaning column at $0.500 \mathrm{~mL} / \mathrm{min}$, a pump flow rate of column loading at $0.300 \mathrm{ml} / \mathrm{min}$, a stabilization temperature at $150^{\circ} \mathrm{C}$, a stabilization time ('pre', prior to load to column ) at $3.0 \mathrm{~min}$, a stabilization time ('post', after loaded to column) at $1.0 \mathrm{~min}$, a SF( Soluble Fraction) time at $3.0 \mathrm{~min}$, a cooling rate of $3.00{ }^{\circ} \mathrm{C} / \mathrm{min}$ from $150{ }^{\circ} \mathrm{C}$ to $30^{\circ} \mathrm{C}$, a flow rate during cooling process of $0.00 \mathrm{ml} / \mathrm{min}$, heating rate of $2.00{ }^{\circ} \mathrm{C} / \mathrm{min}$ from $30^{\circ} \mathrm{C}$ to $160^{\circ} \mathrm{C}$, an isothermal time at $160{ }^{\circ} \mathrm{C}$ for $10 \mathrm{~min}$, an elution flow rate of 0.500 
$\mathrm{mL} / \mathrm{min}$, injection loop size of 140 microliters.

\section{Batch Reactor Polymerization Procedure}

All chemicals used for polymerization or catalyst makeup were run through purification columns to remove any impurities that could affect the polymerization. The Isopar E mixed alkanes solvent, ethylene and propylene were passed through drying columns. A one gallon (3.79 L), stirred autoclave reactor was charged with Isopar E. The reactor was then heated to the desired temperature, and charged with hydrogen (if desired). Propylene was added to the reactor followed by ethylene at the reaction temperature to maintain the reaction pressure setpoint. The catalyst composition was prepared in a drybox, under inert atmosphere, by mixing the desired catalyst and a cocatalyst (a mixture of 1.2 equiv of [HNMe $\left.\left(\mathrm{C}_{18} \mathrm{H}_{37}\right)_{2}\right]\left[\mathrm{B}\left(\mathrm{C}_{6} \mathrm{~F}_{5}\right)_{4}\right]$ and 50 equiv of triisobutylaluminum-modified alumoxane (MMAO-3A)), with additional solvent, to give a total volume of about $17 \mathrm{~mL}$. The activated catalyst mixture was then quickinjected into the reactor. The reactor pressure and temperature were kept constant, by feeding ethylene during the polymerization, and cooling the reactor as needed. After 10 minutes, the ethylene and propylene feeds were shut off, and the solution was transferred into a nitrogen-purged resin kettle. The polymer was thoroughly dried in a vacuum oven, and the reactor was thoroughly rinsed with hot Isopar $\mathrm{E}$ between polymerization runs.

\section{Theoretical number average molecular weight $M_{n(t h e o)}$}

Theoretical number average molecular weight $\mathrm{M}_{\mathrm{n}(\text { theo) }}$ was calculated using $\mathrm{Zn}$ content in polymer assuming that chain transfer to CSA was the only mechanism of molecular weight reduction, using the formula below:

With $\mathrm{ZnEt}_{2}$ :

$$
M_{n(\text { theo })}=1,000,000 \times 65.38 \times 0.5 /(P P M-Z n)
$$

With Zn DHCSA $(n=5)$ :

$$
M_{n(\text { theo })}=1,000,000 \times 65.38 \times 1.2 /(P P M-Z n)
$$

With Zn/Al DHCSA (R/Al/Zn = 4/4/1): 


$$
M_{n \text { (theo) }}=1,000,000 \times 65.38 \times 0.25 /(P P M-Z n)
$$

PPM-Zn is the content of $\mathrm{Zn}$ metal (in ppm) in the polymer measured by XRF. Note that with $\mathrm{ZnEt}_{2}$ as the CSA, each zinc atom can generate two polymer chains $(\mathrm{Zn} / \mathrm{chain}=0.5)$, while with $\mathrm{Zn}$ DHCSA every six zinc atoms generate five polymer chains $(\mathrm{Zn} / \mathrm{chain}=1.2)$, and with $\mathrm{Zn} / \mathrm{Al}$ DHCSA every zinc atom generates four polymer chains $(\mathrm{Zn} / \mathrm{chain}=0.25)$.

\section{TGIC and DSC characterization of block copolymers}

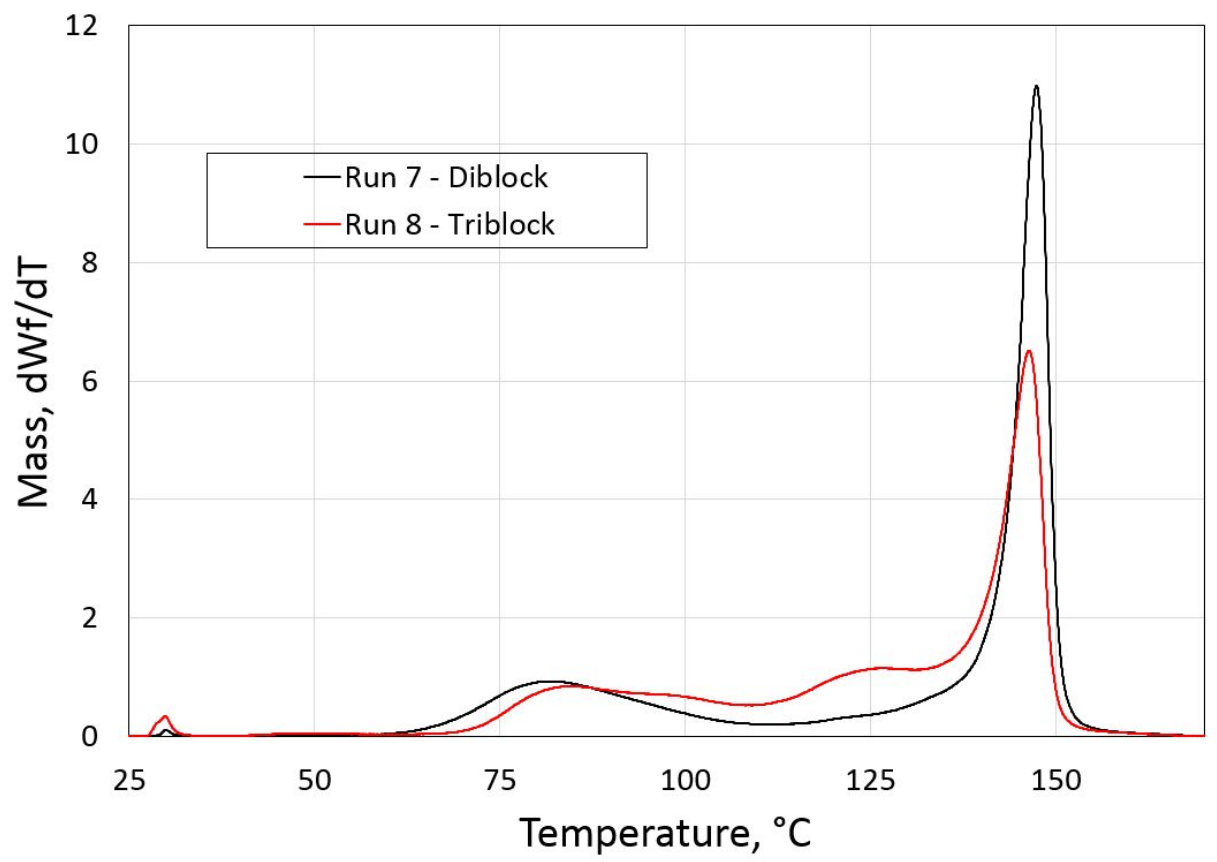

Figure 14S TGIC curves of di- and triblock copolymers 


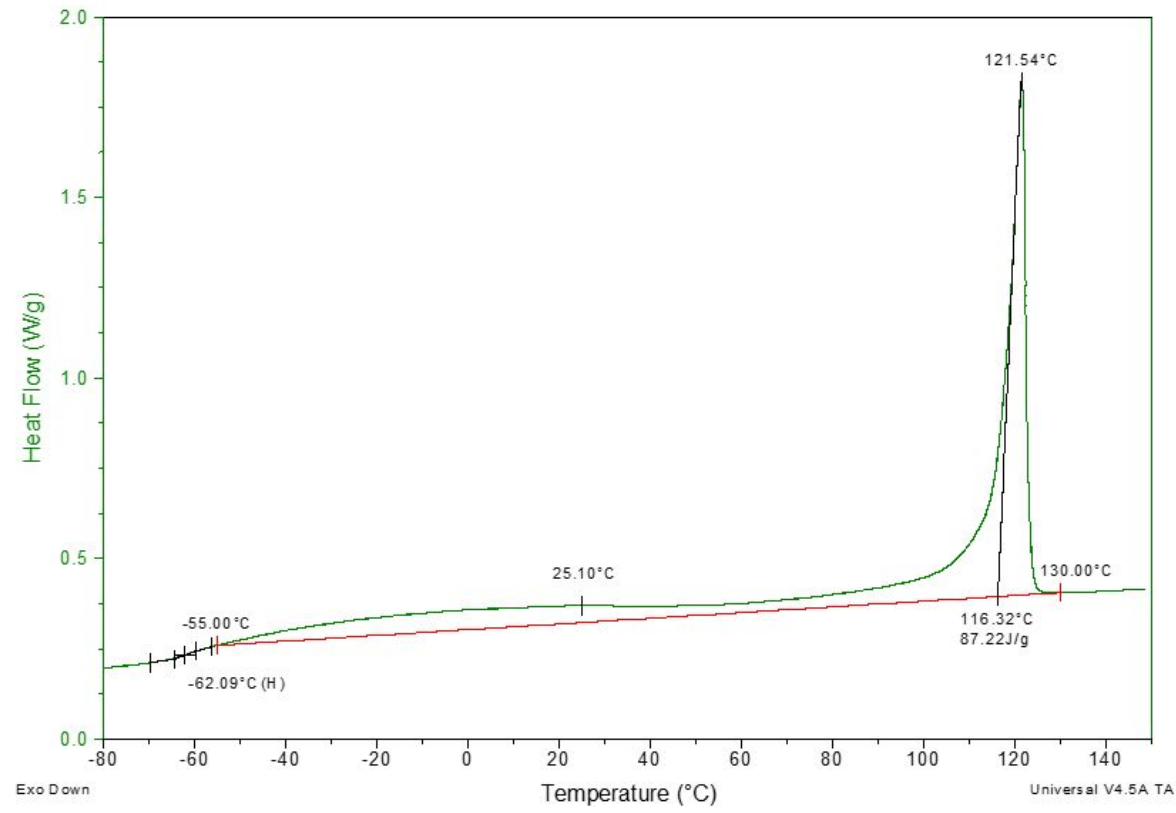

(A) Run 7 - diblock

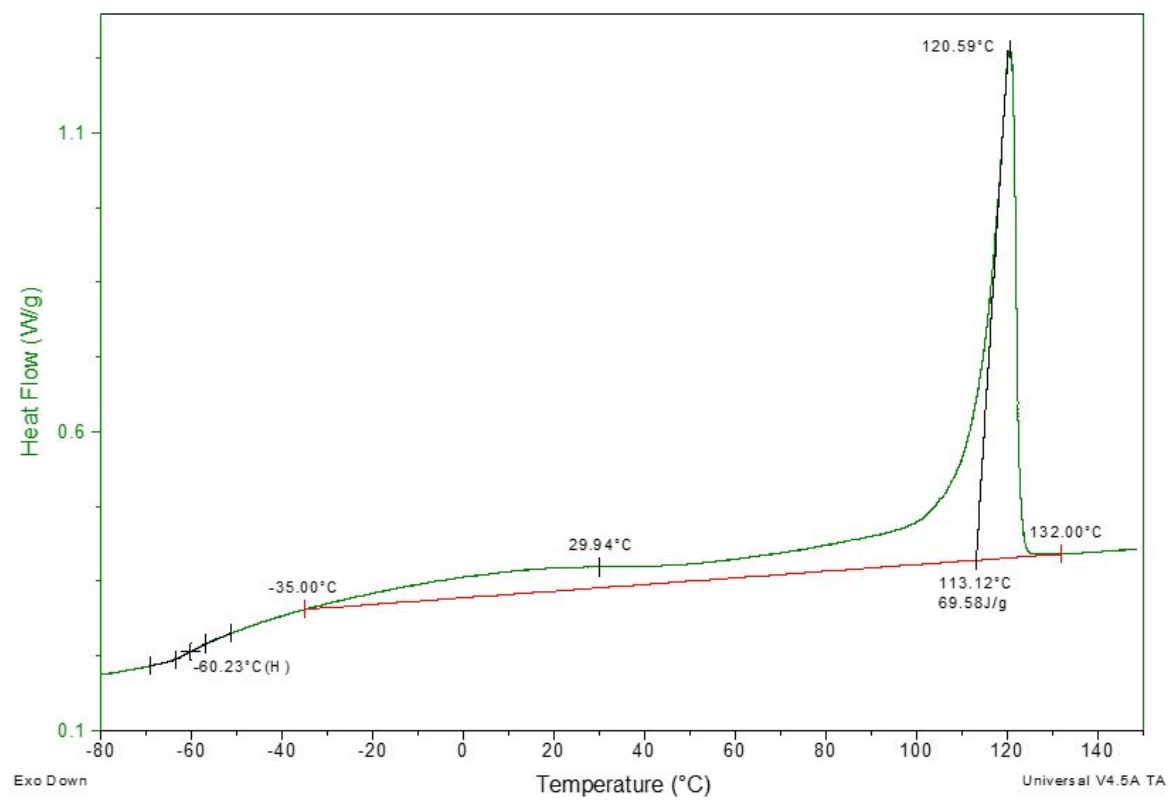

(B) Run 8 - triblock

Figure 15S DSC curves of di- and triblock copolymers 
${ }^{1}$ DD6 is a highly porous activated alumina.

${ }^{2}$ Zhang, C.; Pan, H.; Klosin, J.; Tu, S.; Jaganathan, A.; Fontaine, P. P. Synthetic optimization and scale-up of iminoamido hafnium and zirconium olefin polymerization catalysts. Organic Process Research \& Development 2015, 19, 1383.

${ }^{3}$ Frazier, K. A.; Froese, R. D.; He, Y.; Klosin, J.; Theriault, C. N.; Vosejpka, P. C.; Zhou, Z. Pyridylamido hafnium and zirconium complexes: Synthesis, dynamic behavior, and ethylene/1-octene and propylene polymerization reactions. Organometallics 2011, 30, 3318.

${ }^{4}$ Makio, H.; Kashiwa, N.; Fujita, T. Fl catalysts: a new family of high performance catalysts for olefin polymerization. Adv. Synth. Catal. 2002, 344, 477.

${ }^{5}$ S. Matsui, M. Mitani, J. Saito, N. Matsukawa, H. Tanaka, T. Nakano, T. Fujita, Chem. Lett. 2000, 554

${ }^{6}$ Rosen; Robert K., VanderLende; Daniel D. Highly soluble olefin polymerization catalyst activator, 1999, US $5,919,983$ 